\title{
A Hipótese da Curva de Kuznets Ambiental Global: Uma Perspectiva Econométrico-Espacial
}

\author{
- Terciane Sabadini Carvalho* - Eduardo Almeida**
}

\begin{abstract}
Resumo
Com o objetivo de averiguar a relação entre crescimento econômico e aquecimento global, este trabalho analisa uma curva de Kuznets ambiental por meio de uma abordagem econométrica espacial. Estimou-se uma CKA para emissões de $\mathrm{CO}_{2}$ per capita contra a renda per capita e seu termo ao quadrado, controlando, para exportações per capita, o consumo de energia per capita, uma dummy indicando os países que ratificaram o Protocolo de Kyoto. Os resultados sugerem que existem evidências de uma CKA na forma de " $U$ " invertido, isto é, o crescimento reduz o impacto ambiental da atividade econômica. Porém, a incorporação do termo cúbico para a renda revela que as emissões eventualmente voltam a aumentar em níveis muito elevados de crescimento, fazendo que a CKA global estimada apresente o formato de "N". Outra descoberta foi a evidência de que os países que ratificaram o Protocolo reduziram significativamente suas emissões de $\mathrm{CO}_{2}$ per capita.
\end{abstract}

\section{Palavras-Chave}

Curva de Kuznets Ambiental, emissões de $\mathrm{CO}_{2}$ per capita, econometria espacial, Protocolo de Kyoto

\begin{abstract}
With the aim of checking the relationship between income growth and global warming, the present study analyzes a global environmental Kuznets curve for a sample of 187 countries through a spatial econometric approach. An EKC for conventional per capita $\mathrm{CO}_{2}$ emissions was run on per capita income and its square value, controlling for per capita exports, per capita energy consumption, a dummy variable indicating the countries that ratified the Kyoto Protocol. The results suggested that there is evidence of an inverted $U$ shaped EKC, that is, growth reduces the environmental impact of economic activity. However, the incorporation of a cubic term for per capita income shows that emissions eventually return to increase at a very high level of growth, leading the estimated EKC has an $\mathrm{N}$ shape. Furthermore, another finding was that there are evidences that countries that ratified the Kyoto Protocol reduced significantly their per capita $\mathrm{CO}_{2}$ emissions.
\end{abstract}

\section{Keywords}

Environmental Kuznets Curve, per capita $\mathrm{CO}_{2}$ emissions, spatial econometrics, Kyoto Protocol

\section{JEL Classification}

O53, C21

\footnotetext{
* Departamento de Economia, Universidade Federal de Juiz de Fora (FEA/UFJF). E-mail: tercianesabadini@ yahoo.com.br.

** Departamento de Economia, Universidade Federal de Juiz de Fora (UFJF) e CNPq. E-mail: eduardo. almeida@ufjf.edu.br. O autor agradece o financiamento do Conselho Nacional de Desenvolvimento Científico e Tecnológico (CNPq), da Fundação de Amparo à Pesquisa do Estado de Minas Gerais (Fapemig) e da Universidade Federal de Juiz de Fora (UFJF) para a elaboração deste artigo.

Endereço para contato: Centro de Desenvolvimento e Planejamento Regional - Universidade Federal de Minas Gerais. Av. Antônio Carlos, 6627 - Pampulha - Belo Horizonte - MG. CEP: 31270-901.

(Recebido em fevereiro de 2009. Revisões requeridas em setembro de 2009. Aceito para publicação em outubro de 2009).
} 


\section{Introdução}

A ameaça da mudança climática provocada pelo aquecimento global é uma questão cuja relevância está sendo amplamente reconhecida por muitos especialistas e governos em todo o mundo. A Earth Summit, realizada no Rio de Janeiro em 1992, e a Kyoto Summit, de 1997, têm chamado a atenção internacional sobre as consequências negativas de um aquecimento do planeta, bem como sobre os potenciais instrumentos para lidar com este problema (GALEOTTI; LANZA, 1999).

Segundo o Relatório Brundtland, ${ }^{1}$ os riscos e as incertezas ambientais decorrentes de um consumo elevado de energia no futuro são inquietantes. Dentre os riscos, pode-se destacar a probabilidade de alteração climática devido ao "efeito estufa" causado por gases emitidos na atmosfera, sendo o mais importante deles o dióxido de carbono $\left(\mathrm{CO}_{2}\right)$, que é produzido pela queima de combustíveis fósseis e a poluição do ar urbano pelas indústrias.

Por volta dos anos de 1970, existia uma crença generalizada de que o crescimento econômico de uma nação seria a fonte da maioria dos problemas ambientais. Entretanto, a partir dos anos de 1990, alguns economistas começaram a argumentar que essa visão era extremamente pessimista na medida em que rejeita as alterações educacionais, tecnológicas, econômicas e políticas que acompanham o desenvolvimento de uma nação, que podem amenizar os problemas ambientais. Na verdade, o que se precisa saber, de fato, é se existe um trade-off entre crescimento e poluição, ou se é possível almejar um amadurecimento das economias sem que o meio ambiente seja por isto degradado (FONSECA; RIBEIRO, 2005).

A partir do relatório da Comissão Mundial sobre Meio Ambiente e Desenvolvimento (World Comission on Environmental and Development - WCED), conhecido como Relatório Brundtland (WCED, 1987), foi apresentada a possibilidade de se alcançar a sustentabilidade sem que houvesse mudanças significativas no sistema econômico, lançando a ideia de desenvolvimento sustentável. ${ }^{2}$ Passou-se a ver no desenvolvimento, entendido aqui como crescimento econômico, uma saída para os problemas ambientais no momento em que foram identificadas sinergias entre o crescimento e melhorias ambientais.

1 O relatório Brundtland faz parte de uma série de iniciativas que reafirmam uma visão crítica de desenvolvimento adotado pelos países industrializados e as nações em desenvolvimento, e ressaltam os riscos do uso excessivo dos recursos naturais sem considerar a capacidade de sustentação dos ecossistemas.

2 Desenvolvimento sustentável é definido como o desenvolvimento que atende às necessidades presentes sem comprometer as necessidades futuras. 
Nesse contexto, alguns autores investigaram uma relação que passaria a ser chamada de Curva de Kuznets ${ }^{3}$ Ambiental (CKA), em que algumas medidas de degradação ambiental aumentariam nos momentos iniciais do crescimento econômico, porém, eventualmente, diminuiriam quando certo nível de renda fosse alcançado. ${ }^{4}$

O conceito da CKA surgiu no começo da década de 1990 para descrever a trajetória, no tempo, que a poluição de um país seguirá como resultado do desenvolvimento econômico. Quando o crescimento ocorre em um país extremamente pobre, a poluição inicialmente cresce porque os aumentos na produção geram emissões de poluentes e porque o país, dado sua pobreza, coloca uma baixa prioridade sobre o controle da degradação ambiental. Uma vez que o país ganha suficiente grau de afluência, sua prioridade muda para proteção da qualidade ambiental. Se esse efeito renda é forte o suficiente, causará o declínio da poluição. Segundo Deacon e Norman (2004), tal raciocínio sugere que a melhoria ambiental não pode vir sem crescimento econômico.

Em consonância com essa ideia, os países passariam por estágios de desenvolvimento, regidos pelas forças de mercado e por mudanças na regulação governamental. No primeiro estágio, marcado pela transição de uma economia tradicional agrícola para uma industrializada, o crescimento econômico implica uma pressão cada vez maior sobre o meio ambiente, ${ }^{5}$ resultado da criação e ampliação do parque industrial. $\mathrm{O}$ estágio seguinte seria caracterizado pela maturação da sociedade e da infraestrutura industrial. Nesse ponto, o atendimento das necessidades básicas permite o crescimento de setores menos intensivos em recursos e poluição, e as melhorias técnicas começam a reduzir a intensidade de matéria/energia e rejeitos da produção. Por fim, no terceiro estágio de desenvolvimento, ocorreria o "descolamento" (de-linking) entre o crescimento econômico e a pressão sobre o meio ambiente, a partir do momento em que o primeiro não mais implica um aumento do segundo (GROSSMAN; KRUEGER, 1995; SHAFIK; BANDYOPADHYAY, 1992; SELDEN; SONG, 1994).

Isso tudo implica que o impacto ambiental é uma função na forma de "U" invertido na renda per capita, como é mostrado na Figura 1.

3 A Curva de Kuznets Ambiental foi assim denominada depois de Kuznets (1966), que lançou a hipótese sobre uma relação na forma de " $U$ " invertido entre a medida de desigualdade na distribuição de renda e o nível de renda per capita.

4 De acordo com Stern (2004, p. 1419), "the EKC proposes that indicator of environmental degradation first rise, and then fall with increasing income per capita".

5 Quando se fala dos impactos sobre o meio ambiente, faz-se referência tanto à exploração de recursos naturais (geofísicos e biológicos - inclusive recursos energéticos), quanto à degradação do ambiente natural (geração de resíduos e poluição) e seus efeitos sobre os ecossistemas (LUCENA, 2005). 


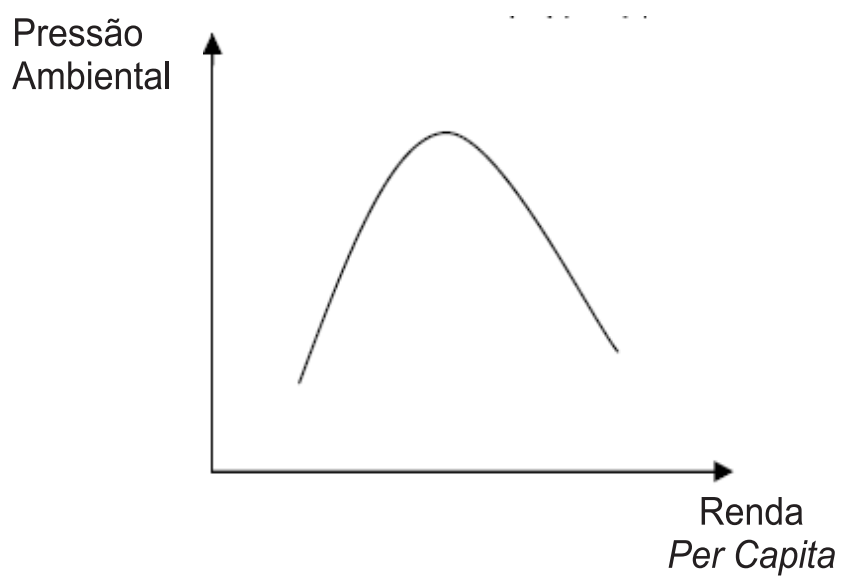

Fonte: Elaboração dos autores.

\section{Figura 1 - Curva de Kuznets Ambiental}

São vários os fatores identificados na literatura que são responsáveis pelo formato descrito pela CKA. A inversão da trajetória positivamente inclinada para uma negativamente inclinada foi atribuída por Selden e Song (1994) a: i) uma elasticidaderenda positiva para qualidade ambiental, ou seja, conforme aumenta a renda, as pessoas tendem a querer mais qualidade ambiental; ii) mudanças na composição da produção e do consumo; iii) níveis maiores de educação ambiental e conscientização das consequências da atividade econômica sobre o meio ambiente, e iv) sistemas políticos mais abertos. Aumento na rigidez da regulação ambiental, melhorias tecnológicas e a liberalização comercial também são apontados como possíveis causadores do "descolamento" (COLE, 2004; STERN, 2004).

Contudo, alguns autores, assim como De Bruyn et al. (1998) acreditam que a CKA não se sustenta no longo prazo. E, então, o formato de "U" invertido seria apenas um estágio inicial da relação entre crescimento econômico e pressão ambiental. Após certo nível de renda, haveria um novo ponto de inflexão que tornaria a trajetória ascendente novamente, e o formato da CKA seria similar ao de um "N", sugerindo que a degradação ambiental voltaria a aumentar em altos níveis de crescimento (Figura 2). 


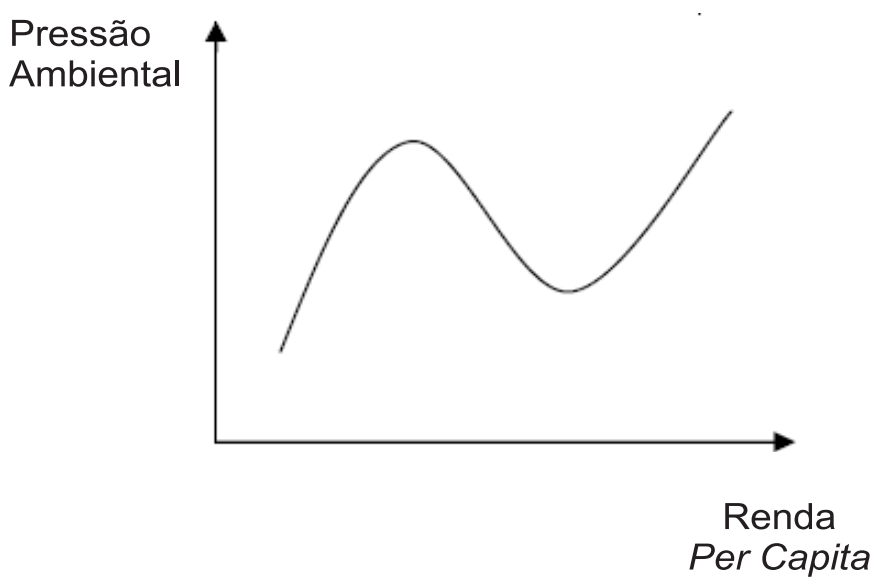

Fonte: Elaboração dos autores.

\section{Figura 2 - Curva de Kuznets Ambiental II}

A decomposição dos efeitos (efeito escala, efeito composição e efeito técnico) que regem a relação entre crescimento econômico e qualidade ambiental, descrita por Grossman e Krueger (1991), é bastante útil para analisar as causas que estão por trás da CKA. É de se esperar que a pressão sobre o meio ambiente aumente conforme haja um aumento de produção (efeito escala). Essa maior pressão, entretanto, pode ser anulada pelo resultado dos outros dois efeitos. Pode ser que o crescimento econômico se dê primordialmente em setores que poluem menos (efeito composição) ou que os avanços tecnológicos na produção compensem o nível de produto maior (efeito técnico). Portanto, não há motivos, a priori, para a qualidade ambiental piorar com o crescimento econômico (TORRAS; BOYCE, 1998). Para Stern (2004), nos países industrializados, onde a taxa de crescimento econômico é baixa, o efeito escala pode ser compensado pelos outros dois efeitos. Isso não ocorre, porém, nos países em desenvolvimento, onde as taxas de crescimento são mais altas. Nesses países, o efeito técnico e o efeito composição não conseguem se sobressair ao efeito escala.

Torras e Boyce (1998), no entanto, afirmam que a mudança na composição da produção não é suficiente para compensar o efeito escala de forma a criar uma trajetória similar à CKA. Desconsiderando o efeito técnico, isso só seria possível se os setores intensivos em poluição diminuíssem em termos absolutos - o que implicaria que os bens produzidos por eles fossem inferiores (isto é, cuja demanda cai conforme a renda aumenta) - ou se a sua produção fosse substituída por importações. Sendo a primeira opção improvável, o que se observa no efeito composição é apenas o deslocamento das atividades nocivas ao meio ambiente para outros países, em geral, países em desenvolvimento. 
Tal conclusão está relacionada à Hipótese dos Portos de Poluição. Segundo Cole (2004), se essa hipótese é verdadeira, então uma CKA não existe. Ela representa apenas uma transferência de poluição entre nações de alta renda para nações mais pobres, o que, por sua vez, impede que a trajetória de desligamento entre crescimento e impacto ambiental seja replicada pelos países em desenvolvimento.

O sucesso na redução das emissões e concentrações de poluentes, tais como o dióxido de enxofre nos países desenvolvidos nas décadas de 1970 e 1980, ajudou a gerar a ideia da CKA no começo da década de 1990 (STERN, 2004). O conceito no qual a poluição primeiro aumenta e então decresce com o crescimento da renda se fortaleceu em crenças preexistentes que países em desenvolvimento são "muito pobres para serem verdes".

Beckerman (1992) enfatizou que existe uma evidência clara de que, embora o crescimento econômico normalmente leve à degradação ambiental nos estágios iniciais do processo, no fim, o melhor e provavelmente o único caminho para se obter um meio ambiente decente, na maioria dos países, é tornando-se rico.

Talvez mais importante do que os resultados encontrados nos estudos que testam empiricamente a CKA sejam as implicações dessa relação em termos de política ambiental. Grossman e Krueger (1995), no entanto, alertam para o fato de que, mesmo para os indicadores de poluição que demonstram uma queda após certo nível de renda, nada garante que tal processo realmente ocorra. Portanto, crescimento econômico por si só não garante a cura para os problemas relacionados ao meio ambiente. As políticas ambientais apropriadas têm papel fundamental na inversão da trajetória dos poluentes que seguem a CKA.

Nesse contexto, o objetivo deste artigo é contribuir para a literatura CKA fornecendo um modelo econométrico mais sofisticado, levando em consideração: as propriedades estatísticas do modelo, a importância das dimensões espaciais em medidas ambientais e a expansão dos determinantes da poluição. Os resultados encontrados sugerem que existe uma relação CKA. Em altos níveis de renda, porém, esse processo se reverte, e a poluição volta a aumentar. Além disso, existem evidências de que os países que ratificaram o Protocolo de Kyoto diminuíram suas emissões de $\mathrm{CO}_{2}$ per capita.

Além dessa introdução, este trabalho está organizado em outras cinco seções. A segunda seção apresenta alguns trabalhos empíricos, indicando a relevância das técnicas metodológicas utilizadas e o avanço presente neste estudo, a terceira descreve o modelo e o método econométrico para a estimação da CKA e a quarta apresenta o 
procedimento de preparação dos dados. Os resultados são analisados, interpretados e discutidos na quarta seção. Por fim, na última seção, tem-se a conclusão.

\section{Revisão da Literatura Empírica}

Segundo Stern (2004), a CKA é um fenômeno essencialmente empírico, mas a maioria da literatura é econometricamente pouco sólida. De um modo geral, pouca ou nenhuma atenção tem sido dispensada às propriedades estatísticas dos dados usados, tais como dependência espacial ou tendências estocásticas em séries de tempo, bem como pouca consideração tem sido dada às questões de adequação do modelo, tal como a possibilidade de viés de variáveis omitidas. A maioria dos estudos assume que, se os coeficientes da regressão são individualmente ou conjuntamente significativos e possuem os sinais esperados, então uma relação CKA existe (MADDISON, 2006; RUPHASINGA et al., 2004). ${ }^{6}$

Recentemente, variáveis explanatórias têm sido incluídas a muitos destes modelos, tais como tarifas de eletricidade, dívida per capita, direitos políticos e comércio. Contudo, no final, a maioria dos estudos conclui que a renda possui o efeito mais significativo sobre a qualidade ambiental dentre todas as variáveis testadas. ${ }^{7}$

Sendo a CKA um resultado empírico, sua validade está sujeita aos seguintes fatores: limitações quanto à disponibilidade e comparabilidade dos dados; vieses relacionados à escolha (ou omissão) de variáveis explicativas e da forma funcional; limitações quanto à capacidade de explicação do modelo; problemas quanto à estacionariedade das séries, entre outros (STERN, 2005; MOOMAW; UNRUH, 1997).

A maioria dos trabalhos desenvolvidos nesta área apresenta dados mundiais, com amostras que incluem um grande número de países. O método de análise, quase sempre, é o de dados em painel e, em menor quantidade, alguns estudos utilizaram análises cross-section. A literatura passou a observar esse tema a partir de Grossman e Krueger (1991) e, desde então, diversos autores publicaram nesta área, com destaque para Shafik e Bandyopadhyay (1992), Stern et al. (1996), Stern (2004),

6 De acordo com Agras e Chapman (1999), o fio comum de todos os modelos já realizados é a estimação de uma relação quadrática, ou log-quadrática, entre alguma medida de degradação ambiental (concentrações ambientais de $\mathrm{SO}_{2}$, emissões de $\mathrm{CO}_{2}$ per capita, falta de água limpa, falta de saneamento urbano, desflorestamento e outros) e a renda per capita para testar o formato de "U" invertido da curva.

7 Um parâmetro-chave desta literatura, segundo Perman e Stern (2003), é o chamado "ponto de inflexão", isto é, o nível de renda per capita em que as emissões ou impactos ambientais atingem seu máximo e então começam a declinar. Stern et al. (1996), Stern (1998) e Stern e Common (2001) afirmam que existe um amplo intervalo entre esses pontos nos diversos estudos, de aproximadamente \$3.000 dólares em Paridade de Poder de Compra (PPC) para acima de \$100.000. 
Selden e Song (1994), entre outros. No Brasil, são poucos os trabalhos sobre a CKA, podendo-se destacar o trabalho de Lucena (2005), que estimou uma curva para o Brasil, e Arraes et al. (2006), que estimou uma curva para diversos países do mundo por meio de uma análise de dados em painel.

Os Quadros 1 e 2 resumem os trabalhos econométricos, ao passo que o Quadro 3 destaca os estudos que utilizaram a econometria espacial.

Por meio dos quadros, percebe-se que os estudos descritos têm obtido resultados e conclusões muito distintos sobre a existência de uma CKA global. Os motivos podem ser amostras de países diferentes, indicadores de degradação ambiental diversificados, técnicas econométricas distintas e pouca análise estatística dos dados.

Além disso, a maioria dos trabalhos sobre a CKA utilizou um modelo de painel de dados sem considerar a dependência espacial. E como áreas geográficas formam a unidade básica da CKA, ignorar a dependência espacial existente pode levar à má especificação do modelo, implicando estimativas inconsistentes e/ou ineficientes.

Outra questão relevante são as diferenças estruturais entre os diversos países, mostrando que existem razões pelas quais é importante considerar explicitamente a heterogeneidade espacial. A estrutura por trás da instabilidade é espacial (ou geográfica), no sentido de que a localização das observações é fundamental para determinar a forma da instabilidade. Os países são muito diferentes e possuem características próprias que podem afetar as suas emissões, como o clima, a cultura e a dotação de recursos (SURI; CHAPMAN, 1998). Esses aspectos mudam entre os países, embora mudem muito lentamente através do tempo.

Ademais, as interações espaciais são muito importantes nas CKA's, porque as emissões per capita dos países são afetadas por eventos ocorridos em países vizinhos. As muitas fontes dessa interação espacial são discutidas em Maddison (2006).

Trabalhos com econometria espacial envolvendo emissões de $\mathrm{CO}_{2}$ para anos recentes, como 2004, não foram encontrados durante o período da elaboração deste artigo. Portanto, o presente estudo tentará cobrir essa possível lacuna da literatura e, então, estimar uma CKA global utilizando esse poluente como medida de degradação ambiental. 


\begin{tabular}{|c|c|c|c|c|c|c|}
\hline 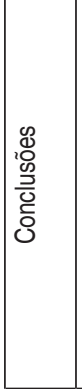 & 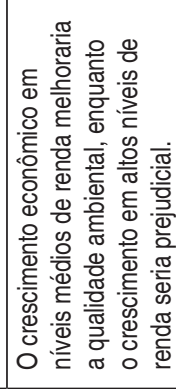 & 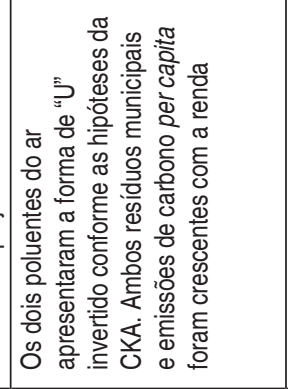 & 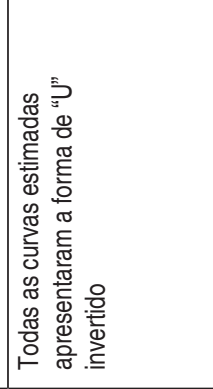 & 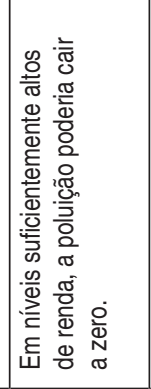 & 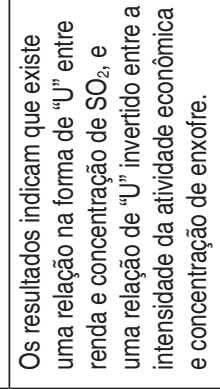 & 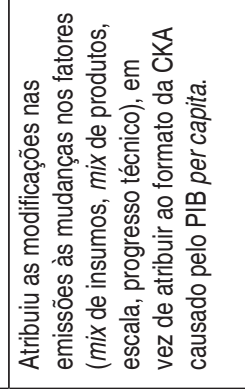 \\
\hline 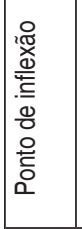 & 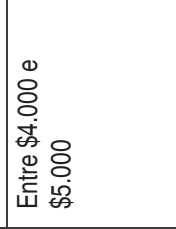 & 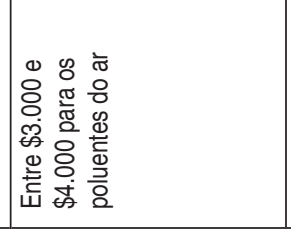 & 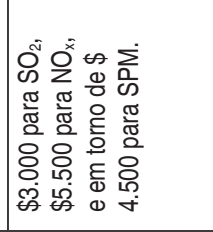 & 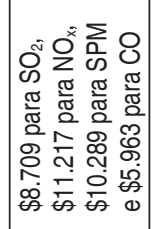 & 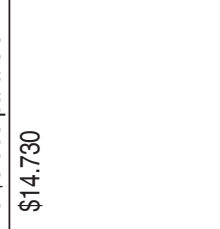 & 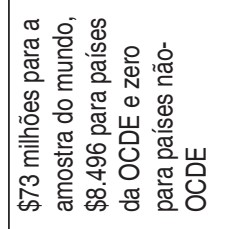 \\
\hline 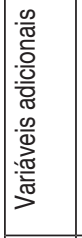 & 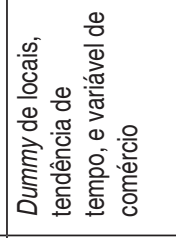 & 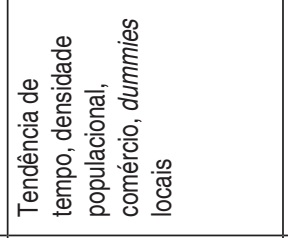 & 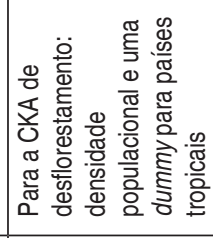 & 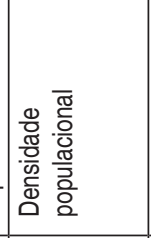 & 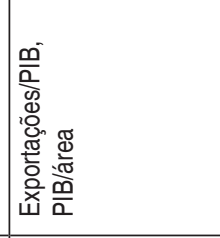 & 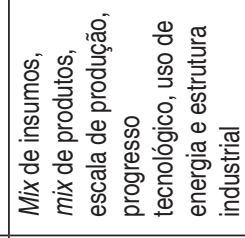 \\
\hline 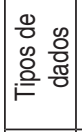 & 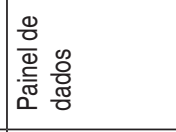 & 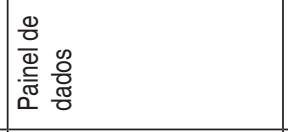 & 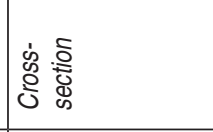 & 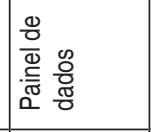 & 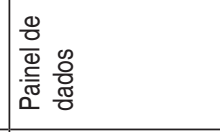 & 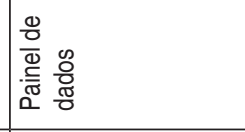 \\
\hline 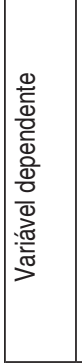 & 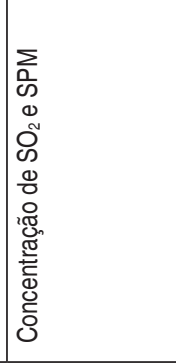 & 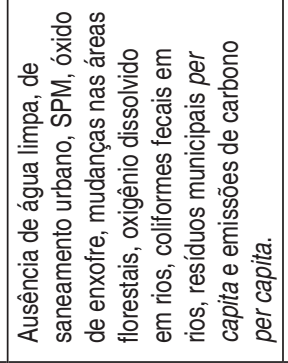 & 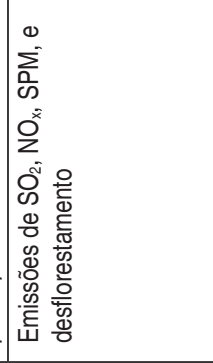 & 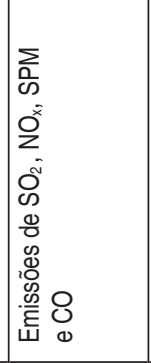 & 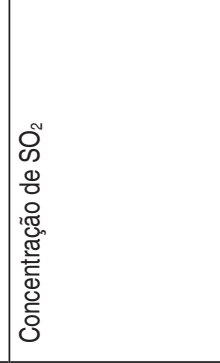 & 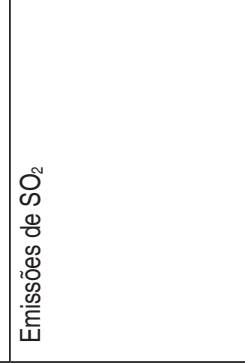 \\
\hline 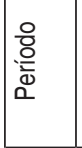 & 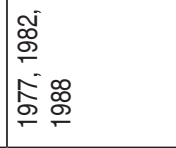 & $\begin{array}{l}\text { 욤 } \\
\frac{0}{6} \\
\frac{0}{9}\end{array}$ & $\begin{array}{l}\infty \\
\infty \\
\frac{\infty}{1} \\
\stackrel{\infty}{\infty} \\
\stackrel{\circ}{\circ}\end{array}$ & 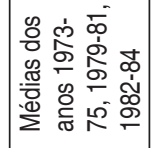 & 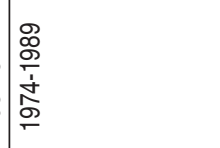 & 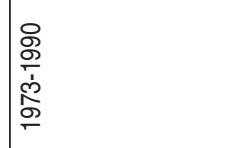 \\
\hline 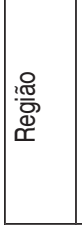 & 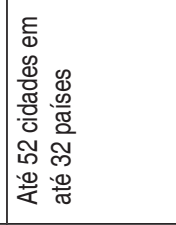 & 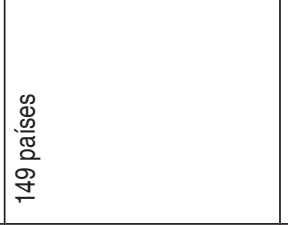 & 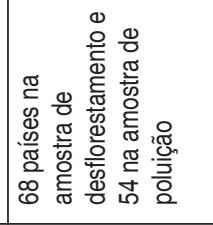 & 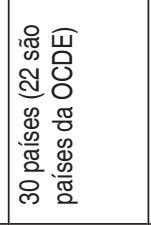 & 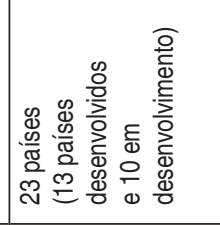 & 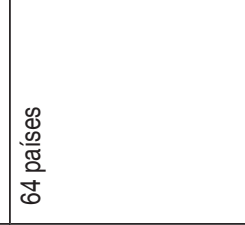 \\
\hline 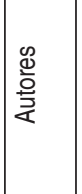 & 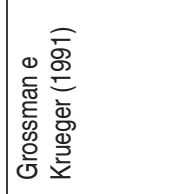 & 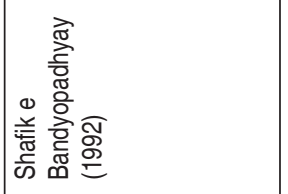 & 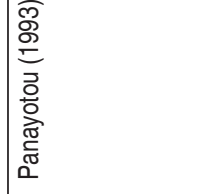 & 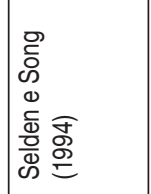 & 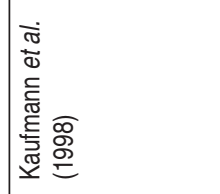 & 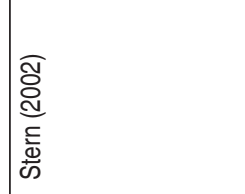 \\
\hline
\end{tabular}




\begin{tabular}{|c|c|c|c|c|c|}
\hline 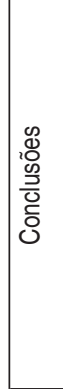 & 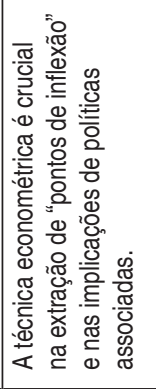 & 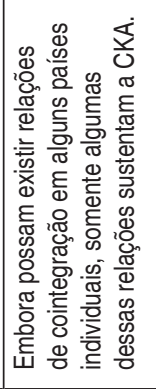 & 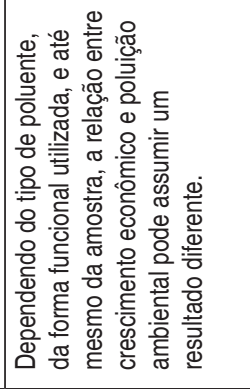 & 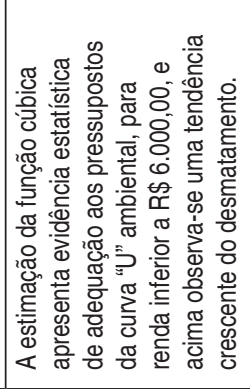 & 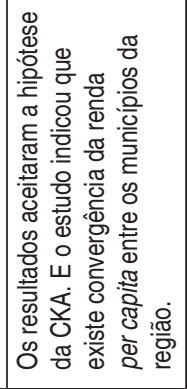 \\
\hline 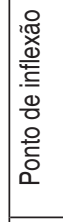 & 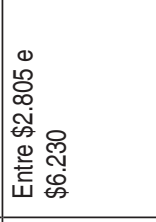 & 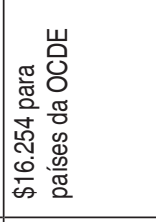 & & & \\
\hline 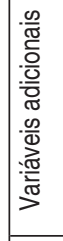 & 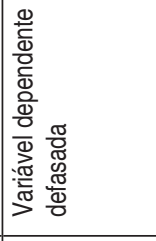 & 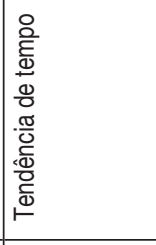 & 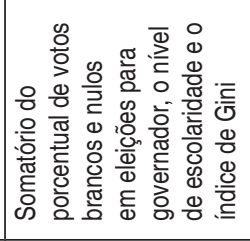 & 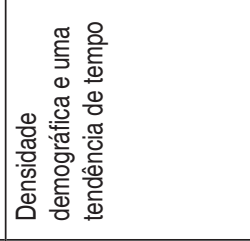 & \\
\hline 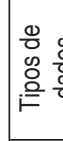 & 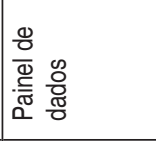 & 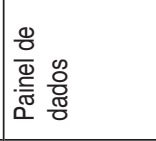 & 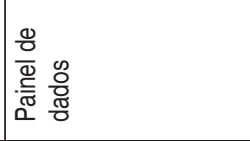 & 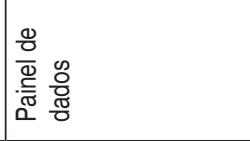 & 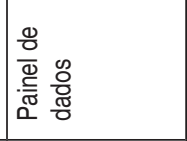 \\
\hline 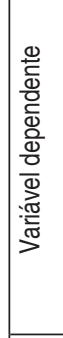 & 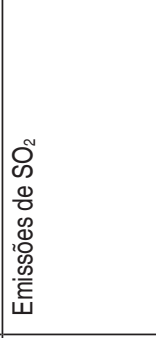 & 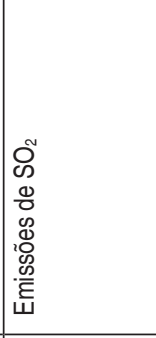 & 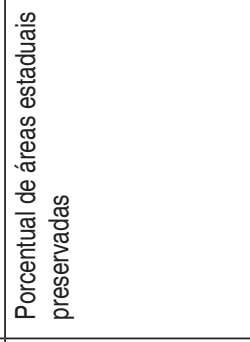 & 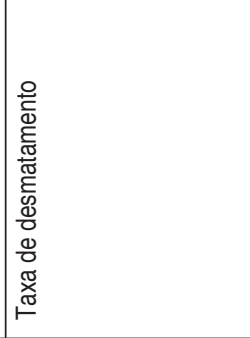 & 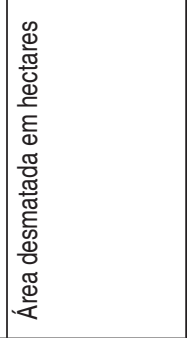 \\
\hline $\begin{array}{l}\text { 음 } \\
\text { 흠 } \\
\end{array}$ & 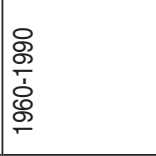 & 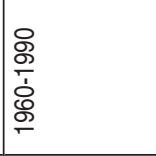 & 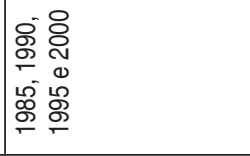 & 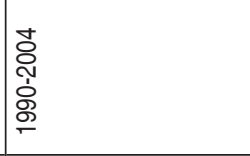 & 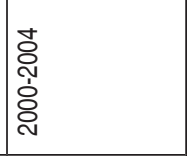 \\
\hline 遂 & 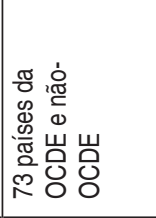 & 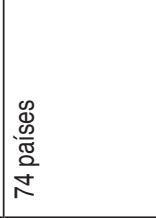 & 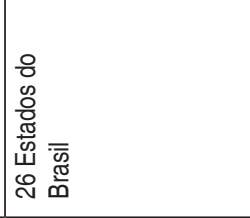 & 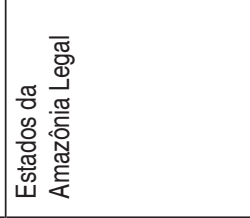 & 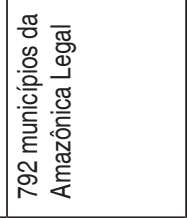 \\
\hline 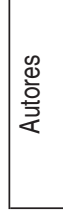 & 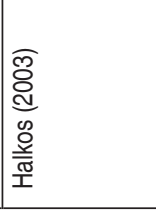 & 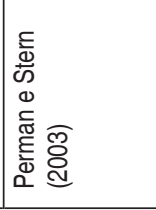 & 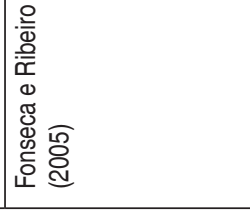 & 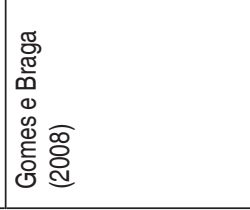 & 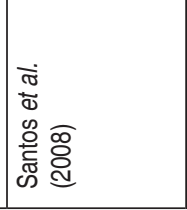 \\
\hline
\end{tabular}




\begin{tabular}{|c|c|c|c|c|c|c|c|}
\hline 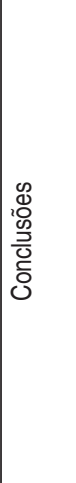 & 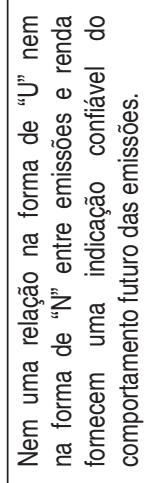 & 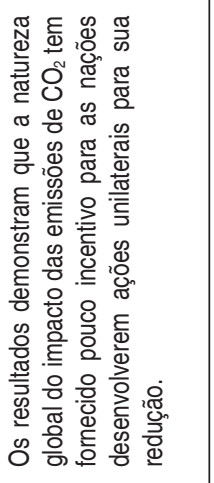 & 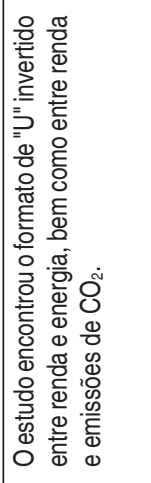 & 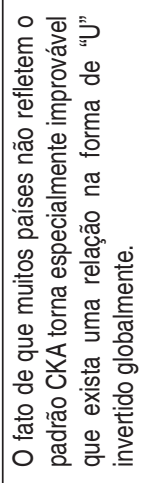 & 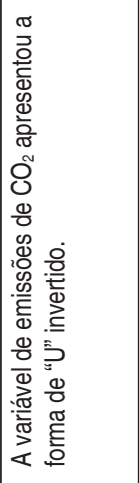 & 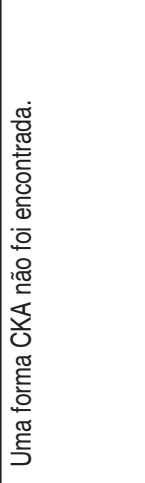 & 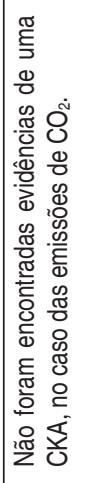 \\
\hline 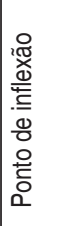 & $\begin{array}{l}\frac{m}{\infty} \\
\stackrel{\infty}{\infty} \\
\stackrel{\omega}{\infty}\end{array}$ & 음 & 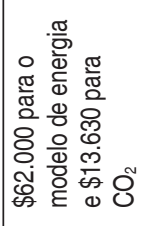 & 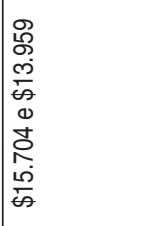 & & & \\
\hline 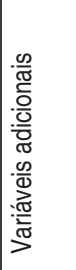 & & 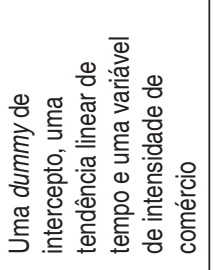 & 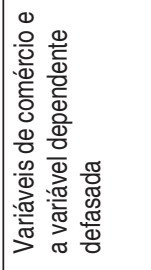 & & 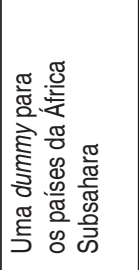 & 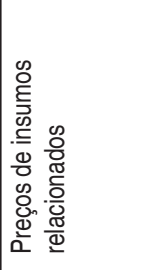 & 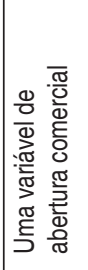 \\
\hline 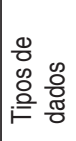 & 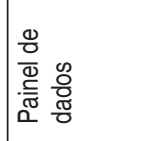 & 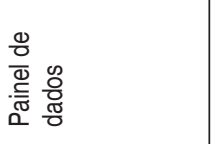 & 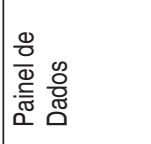 & 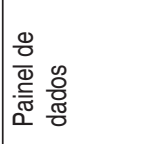 & 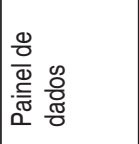 & 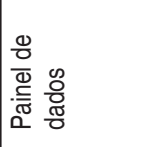 & 䨌 \\
\hline 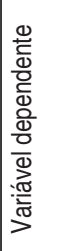 & 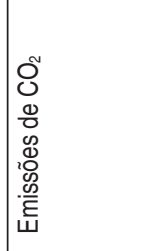 & 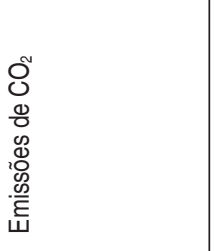 & 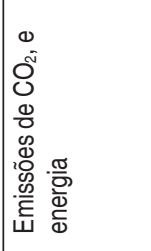 & 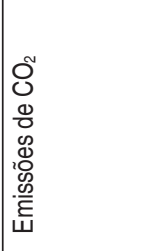 & 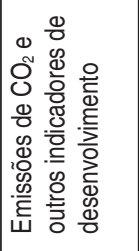 & 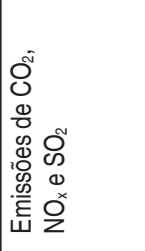 & 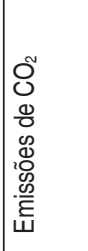 \\
\hline$\frac{\text { 응 }}{\text { 음 }}$ & 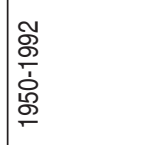 & $\begin{array}{l}\overline{8} \\
\frac{\sigma}{6} \\
\stackrel{0}{\leftarrow}\end{array}$ & 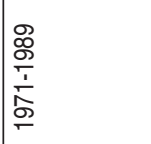 & \begin{tabular}{l} 
ळे \\
$\frac{\sigma}{\delta}$ \\
$\varnothing$ \\
\hdashline
\end{tabular} & 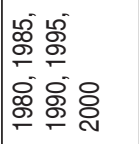 & 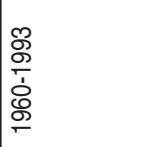 & 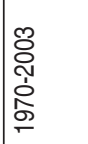 \\
\hline $\begin{array}{l}\frac{\mathbb{8}}{\overline{7}} \\
\frac{\mathbb{d}}{\pi}\end{array}$ & 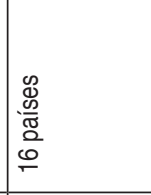 & 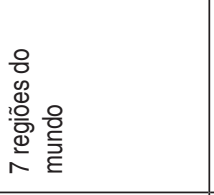 & 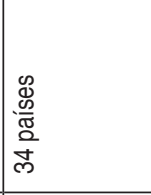 & 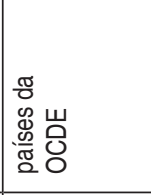 & 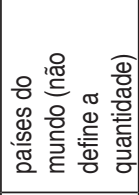 & 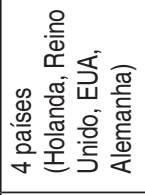 & \begin{tabular}{|l}
$\overline{\bar{g}}$ \\
$\frac{\tilde{m}}{\bar{\omega}}$
\end{tabular} \\
\hline 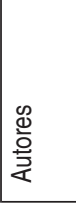 & 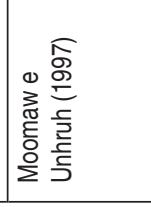 & 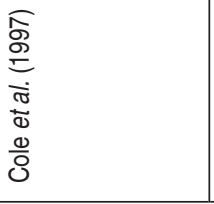 & 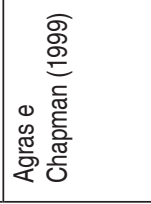 & 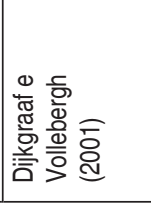 & 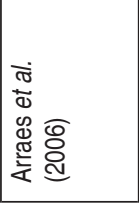 & 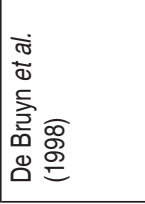 & 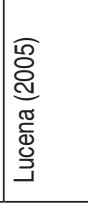 \\
\hline
\end{tabular}




\begin{tabular}{|c|c|c|c|c|}
\hline 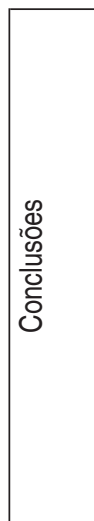 & 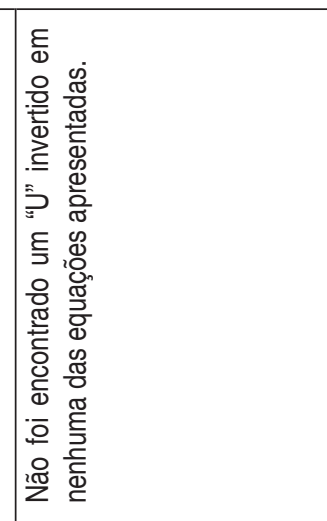 & 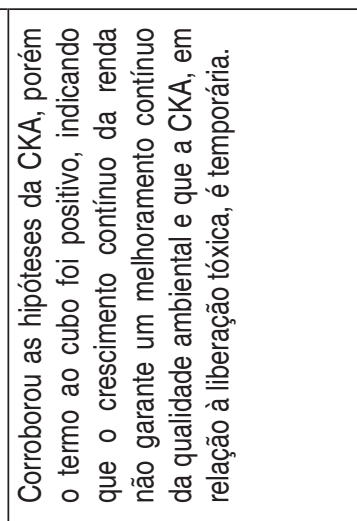 & 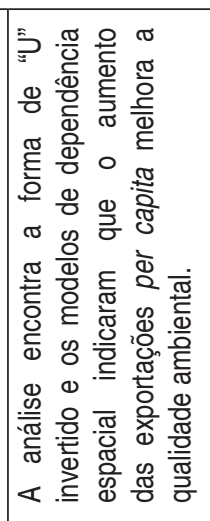 & 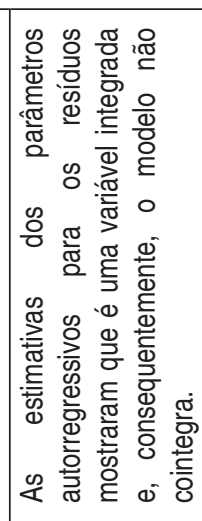 \\
\hline 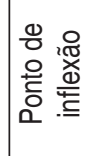 & & 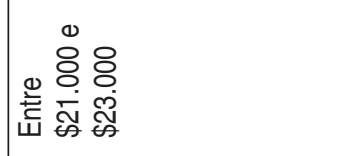 & & 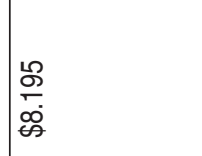 \\
\hline 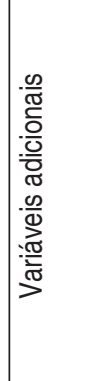 & 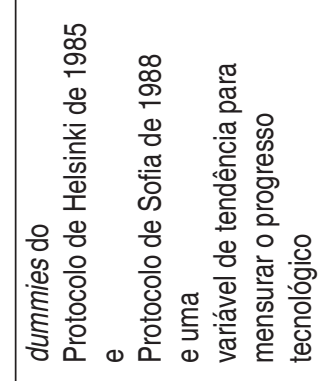 & 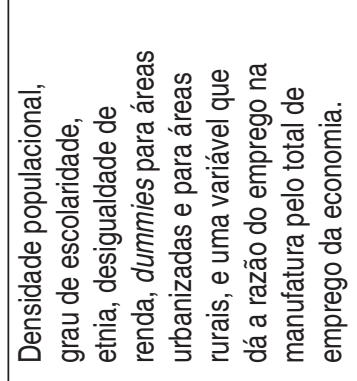 & 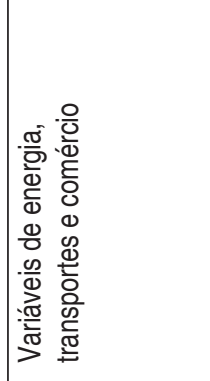 & 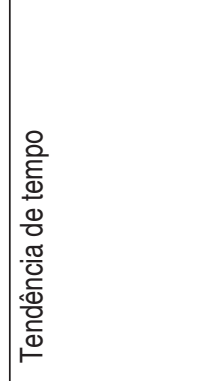 \\
\hline 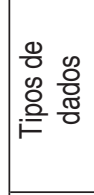 & 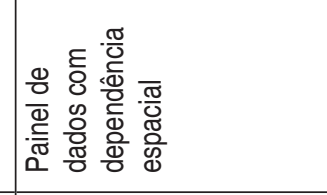 & 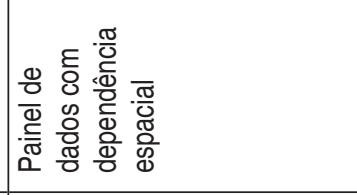 & 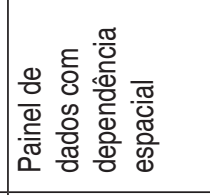 & 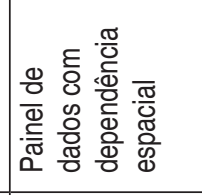 \\
\hline 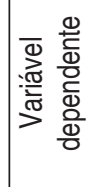 & $\begin{array}{l}\approx 0 \\
20 \\
20 \\
00 \\
08\end{array}$ & 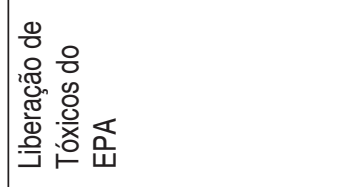 & 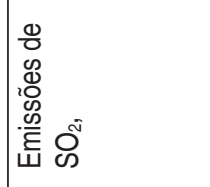 & 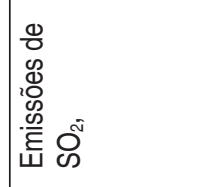 \\
\hline $\begin{array}{l}\frac{0}{0} \\
\overline{\bar{D}} \\
0\end{array}$ & ஓ̊ & 总 & 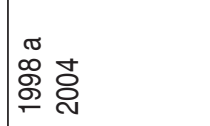 & চ্் \\
\hline 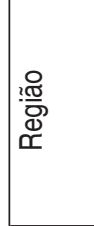 & 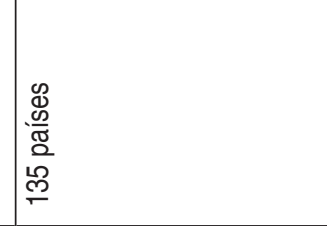 & 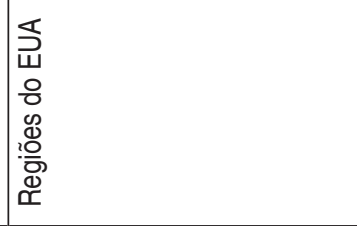 & 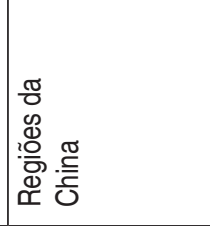 & 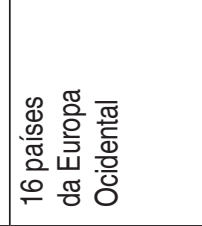 \\
\hline 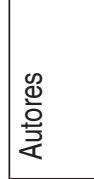 & 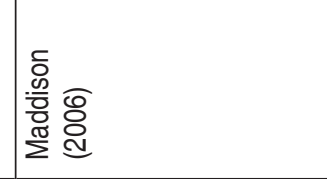 & 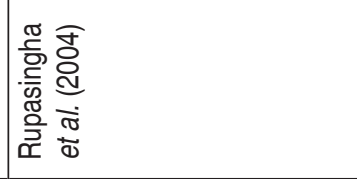 & 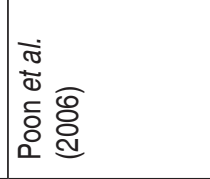 & 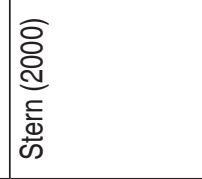 \\
\hline
\end{tabular}


O presente estudo avança principalmente na discussão sobre a CKA em quatro aspectos. Em primeiro lugar, na revisão da literatura realizada, não se encontrou um trabalho empírico de CKA com $\mathrm{CO}_{2}$ como indicador de degradação ambiental, controlando-se para efeitos espaciais. Em segundo lugar, pode-se salientar que nenhum estudo cross-section anterior apresentou esse tamanho amostral. Em terceiro lugar, a análise é aplicada para um ano recente (2004). E, por fim, uma variável adicional é inserida na análise para investigar se um país que ratificou o Protocolo de Kyoto contribuiu efetivamente ou não para a redução das emissões.

\section{Especificação do Modelo}

A especificação do modelo foi baseada em estudos anteriores da CKA, que utilizaram algumas medidas de emissões de poluentes como variável dependente, e o PIB per capita e o seu quadrado como as mais importantes variáveis explicativas. Neste trabalho, porém, somente uma medida de emissão será considerada, o dióxido de carbono $\left(\mathrm{CO}_{2}\right)$, por ser o principal responsável pelo "efeito estufa" e, consequentemente, do fenômeno do aquecimento global.

De um ponto de vista teórico, a relação na forma de "U" invertido é menos provável para as emissões de $\mathrm{CO}_{2}$ do que para poluentes do ar "tradicionais", tais como o $\mathrm{SO}_{2}$; porque, enquanto esses poluentes possuem efeitos locais, as emissões de carbono causam problemas em escala global e, assim, os custos sociais do aquecimento global se acumulam ao longo do tempo e através das nações. Desse modo, é preciso haver incentivos multilaterais para que se possa almejar uma redução da quantidade de $\mathrm{CO}_{2}$ emitida. Por esse motivo, para a estimação de uma CKA global, este estudo conta com um painel de 187 países.

Limitou-se a análise para examinar se existe dependência espacial para uma CKA com a existência de dados para o ano de 2004. Expandiram-se os determinantes das emissões de $\mathrm{CO}_{2}$, introduzindo duas variáveis explanatórias adicionais, ou seja, as exportações per capita e o consumo de energia per capita. Além destas, uma variável dummy também foi adicionada à regressão, assumindo o valor "um" para os países que ratificaram o Protocolo de Kyoto, e "zero" caso contrário.

O modelo empírico econométrico apresenta a seguinte forma:

$$
\begin{aligned}
& E_{i}=c+\rho W_{1} E_{i}+\beta_{1} Y_{i}+\beta_{2} Y_{i}^{2}+\beta_{3} Y_{i}^{3}+\theta P K_{i}+\omega C E_{i}+\psi E X_{i}+u_{i} \\
& u_{i}=\lambda W_{2} u_{i}+\varepsilon_{i}
\end{aligned}
$$


na qual $E_{i}$ representa as emissões de dióxido de carbono per capita no país $i$; $c$ é a constante, $W_{1} E_{i}$ é a defasagem espacial da variável dependente; $Y_{i}$ é o símbolo para o PIB per capita no país $i$; $Y_{i}^{2}$ é o quadrado da variável $Y_{i}$; $Y_{i}^{3}$ é o cubo da variável $Y_{i}, P K_{i}$ é uma variável dummy para os países que ratificaram o Protocolo de Kyoto, $C E_{i}$ representa o consumo de energia per capita do país $i$; $E X_{i}$ são as exportações per capita no país $i$, e $W_{2} u_{i}$ é a defasagem espacial do termo de erro. $W_{1}$ e $W_{2}$ são matrizes de pesos espaciais, que tentam capturar a estrutura de dependência espacial. O termo de erro $\varepsilon_{i}$ tem média zero e variância constante. As outras letras gregas são os parâmetros a serem estimados.

Se algumas restrições forem colocadas sobre a equação (1), têm-se alguns modelos econométricos espaciais, os quais consideram a autocorrelação espacial. Se $\lambda=0 \mathrm{e}$ $\rho \neq 0$, tem-se o modelo de defasagem espacial. Esse tipo de modelo representa os efeitos dos transbordamentos da degradação ambiental. Nesse caso, na presença da variável dependente defasada espacialmente, que possui uma natureza endógena, os estimadores MQO serão enviesados e inconsistentes se esta variável for ignorada. Para se evitar tais problemas, recomendam-se alguns métodos de estimação alternativos, como o uso de Variáveis Instrumentais (VI) e o método de máxima verossimilhança.

Se $\rho=0$ e $\lambda \neq 0$, o modelo de erro espacial é obtido. Tal modelo é mais apropriado quando existem fatores não modelados que se manifestam nos resíduos. Segundo Rey e Montouri (1999), se $\lambda \neq 0$, um choque ocorrido em uma unidade geográfica se espalha não só para seus vizinhos imediatos, mas por todas as outras unidades. O modelo irrestrito é um modelo que apresenta defasagem espacial e erro espacial. $^{8}$

Para que a hipótese CKA na forma de um "U" invertido seja válida, o coeficiente $\beta_{1}$ precisa ser positivo e significativo, ao passo que o coeficiente estimado $\beta_{2}$ precisa ter o sinal negativo e significativo e o coeficiente $\beta_{3}$ não ser significativamente diferente de zero. Se $\beta_{3}$ for significativo e tiver o sinal positivo, isso representaria evidências de que a CKA possui a forma de "N".

Teoricamente, as emissóes de $\mathrm{CO}_{2}$ devem aumentar quando o consumo de energia em um país também aumenta, por isso espera-se que o sinal de $\omega$ seja positivo. No

8 Para mais informações sobre modelos espaciais, veja Anselin (1988) e Anselin e Bera (1998). 
caso das exportações, ${ }^{9}$ como destaca Stern et al. (1996), a mudança dos padrões internacionais de qualidade ambiental e mudanças estruturais dentro das economias levarão os países a se especializarem em atividades que usam menos recursos naturais e energia, assim espera-se que o sinal de $\psi$ seja negativo. Isso quer dizer que um país, ao aumentar as suas exportações e, consequentemente, sua participação no comércio internacional, proporcionaria impactos positivos ao meio ambiente (POON et al., 2006). A variável de comércio foi incluída sob a hipótese de que o nível de poluição de um país pode estar diretamente relacionado à sua abertura ao comércio internacional, talvez porque as regulamentações ambientais tendem a um mínimo denominador comum (STERN et al. 1996). E, por fim, como os países que ratificaram o Protocolo de Kyoto se comprometeram a reduzir suas emissões em 5,2\% até 2012, o coeficiente esperado para $\theta$ também é negativo.

\section{Dados}

A amostra contém 187 dados em corte cruzado para o ano de 2004. A variável dependente são as emissões de $\mathrm{CO}_{2}$ per capita (em toneladas métricas). A razão da escolha do indicador em "emissões" e não "concentração" é porque as emissões estão ligadas a níveis correntes de atividade econômica, então, elas medem o potencial para a atividade econômica de danificar o meio ambiente e/ou a saúde humana (KAUFMANN et al., 1998). Os dados são da Divisão de Estatísticas das Nações Unidas (United Nations Statistics Division - UNSD), o qual reúne informações de outras duas fontes, o CDIAC (Carbon Dioxide Information Analysis Center) e o MDG (Millennium Development Goals).

A principal variável explicativa, o PIB per capita, está medida em dólares a preços correntes e foi obtida das estimativas das Nações Unidas. Segundo Stern et al. (1996) e Panayotou (1993), em altos níveis de crescimento econômico, mudanças estruturais em direção a indústrias e serviços, que são intensivas em informação, juntamente com uma maior conscientização e crescente regulamentação ambiental, maiores gastos ambientais e melhores tecnologias, resultam em um gradual declínio da degradação do meio ambiente. Portanto, essa variável tem como objetivo averiguar se existe a relação na forma de "U" invertido para a CKA global.

Os dados para a população foram extraídos das projeções anuais e estimativas da Divisão de População das Nações Unidas. O consumo de energia (em milhares de

9 Uma medida de intensidade de comércio (exportações mais importações divididas pelo PIB) poderia ser mais adequada para medir o grau da abertura comercial de um país, porém, devido a pouca disponibilidade de dados mundiais e o fato de que muitos autores utilizaram as exportações como grau de abertura, tais como Kaufmann et al. (1998), Poon et al. (2006), justificam a escolha dessa variável. 
toneladas de petróleo equivalente) foi retirado da UNSD. Se a energia é usada em todos os lugares, e a maioria das formas de sua utilização liberam poluentes, seria necessário adicionar uma proxy para avaliar a relação entre energia e índices de degradação ambiental (AGRAS; CHAPMAN, 1999). Isso ocorre, também, porque as emissões de $\mathrm{CO}_{2}$ aumentam devido ao uso de combustíveis (energia) fósseis; o objetivo dessa variável é mostrar que o aumento do consumo de energia aumenta a quantidade de carbono emitida.

As exportações (em milhões de dólares F.O.B.) foram extraídas do FMI (International Monetary Fund - IMF). Segundo Stern et al. (1996), grande parte da redução da razão energia/PIB nas economias individuais ao longo do tempo e as variações internacionais da razão energia/PIB são devidas às mudanças estruturais dentro das economias e às diferenças estruturais entre elas. Ele afirma, ainda, que a "suposição de que mudanças nas relações de comércio associadas com o desenvolvimento não têm efeito sobre a qualidade ambiental" (Stern et al., p. 1155) limita muito as conclusões alcançadas pelas análises CKA. Portanto, o objetivo desta variável é mostrar que, quanto maior for a abertura comercial dos países, menor será a degradação ambiental na forma de emissões de $\mathrm{CO}_{2}$.

O Quadro 4 apresenta um resumo da descrição de todas as variáveis usadas no presente trabalho para a estimação de uma CKA global. E a Tabela 1 apresenta algumas estatísticas descritivas do conjunto de dados. 


\begin{tabular}{|c|c|c|c|c|}
\hline Variável & Descrição & $\begin{array}{c}\text { Sinal } \\
\text { Esperado }\end{array}$ & Referencial Empírico & Fonte \\
\hline$E_{i}$ & $\begin{array}{l}\text { Razão das emissões totais de } \\
\text { dióxido de carbono }\left(\mathrm{CO}_{2}\right) \text { de } \\
\text { um país pela sua população }\end{array}$ & & $\begin{array}{l}\text { Agras e Chapman (1999), } \\
\text { Cole et al. (1997), Dijkgraaf e } \\
\text { Vollebergh (2001) (2001) }\end{array}$ & $\begin{array}{l}\text { UNSD, CDIAC e } \\
\text { MDG }\end{array}$ \\
\hline$Y_{i}$ & $\begin{array}{l}\text { Razão do Produto Interno } \\
\text { Bruto de cada país pela sua } \\
\text { população }\end{array}$ & + & $\begin{array}{l}\text { Grossman e Krueger (1991), } \\
\text { Selden e Song (1994), } \\
\text { Kaufmann et al. (1998) }\end{array}$ & $\begin{array}{l}\text { Nações Unidas } \\
\text { (UN) }\end{array}$ \\
\hline$Y_{i}^{2}$ & O quadrado da variável $Y_{i}$ & - & $\begin{array}{l}\text { Grossman e Krueger (1991), } \\
\text { Selden e Song (1994), } \\
\text { Kaufmann et al. (1998) }\end{array}$ & $\begin{array}{l}\text { Nações Unidas } \\
\text { (UN) }\end{array}$ \\
\hline$Y_{i}^{3}$ & $\begin{array}{l}\text { A variável } Y_{i} \text { elevada ao } \\
\text { cubo }^{10}\end{array}$ & * & $\begin{array}{l}\text { Grossman e Krueger (1991), } \\
\text { Moomaw e Unruh (1997), } \\
\text { Maddison (2006) }\end{array}$ & $\begin{array}{l}\text { Nações Unidas } \\
\text { (UN) }\end{array}$ \\
\hline$P K_{i}$ & $\begin{array}{l}\text { Assume valor "1" para os países } \\
\text { que ratificaram o Protocolo } \\
\text { de Kyoto e "0 (zero)", caso } \\
\text { contrário }\end{array}$ & - & & $\mathrm{IEA}^{11}$ \\
\hline$E X_{i}$ & $\begin{array}{l}\text { Razão das exportações de } \\
\text { cada país pela população }\end{array}$ & - & $\begin{array}{l}\text { Agras e Chapman (1999), } \\
\text { Kaufmann et al. (1998) }\end{array}$ & $\begin{array}{l}\text { Fundo Monetário } \\
\text { Internacional - } \\
\text { IMF }\end{array}$ \\
\hline$C E_{i}$ & $\begin{array}{l}\text { Razão do consumo de energia, } \\
\text { medido em mil toneladas } \\
\text { equivalentes de petróleo, pela } \\
\text { população }\end{array}$ & + & Cole et al. (1997) & UNSD \\
\hline
\end{tabular}

Quadro 4 - Descrição das Variáveis

Tabela 1 - Descrição do Conjunto de Dados

\begin{tabular}{lrrrrr}
\hline Variável & \multicolumn{1}{c}{ Média } & Desvio Padrão & \multicolumn{1}{c}{ Máximo } & \multicolumn{1}{c}{ Mínimo } & Coeficiente de Variação \\
\hline$E_{i}$ & 5,413 & 7,997 & $69,221^{*}$ & $0,013^{* *}$ & $147 \%$ \\
$Y_{i}$ & 9153,160 & 14062,268 & 73189,000 & 94,000 & $154 \%$ \\
$C E_{i}$ & 1,933 & 3,153 & 29,082 & 0,004 & $163 \%$ \\
$E X_{i}$ & 3573,528 & 8231,980 & 72219,802 & 6,326 & $230 \%$ \\
\hline
\end{tabular}

Fonte: Elaboração dos autores.

* O valor máximo foi encontrado para o Qatar.

** O valor mínimo foi encontrado para o Chad.

10 Espera-se que a variável $Y_{i}^{3}$ apresente um coeficiente nulo, o que corroboraria a hipótese de um formato de "U" invertido da CKA, porém os estudos que incorporaram esta variável encontraram um coeficiente com sinal positivo, indicando que a CKA apresenta uma forma de "N".

11 IEA - Instituto de Economia Agrícola. 


\section{Análise dos Resultados}

As estatísticas I de Moran, $c$ de Geary e $G$ de Getis-Ord fornecem uma indicação do grau de autocorrelação espacial. Contudo, para implementar esses indicadores, é necessário escolher uma matriz de pesos espaciais $W$. Na literatura, existem muitos exemplos desses tipos de matrizes. Com a finalidade de reduzir o problema de "ilhas", ${ }^{12}$ foi utilizada neste trabalho a matriz $W$, baseada na ideia dos $k$ vizinhos mais próximos, $w_{i j}(k)$. Para tornar a escolha do valor de $k$ menos arbitrária, o procedimento de Baumont (2004) foi adotado. Por fim, definiu-se $k=2$, pois este gerou o mais alto valor $I$ de Moran.

As estatísticas $I, c$, e G são reportadas na Tabela 2.

Tabela 2 - Indicadores de Autocorrelação Espacial

\begin{tabular}{lccccc}
\hline Indicador & Coeficiente & Média & Desvio Padrão & z-valor & P-valor \\
\hline I de Moran & 0,624 & $-0,005$ & 0,066 & 9,532 & 0,000 \\
c de Geary & 0,626 & 1,000 & 0,072 & $-5,192$ & 0,000 \\
G de Getis-Ord & 0,0269 & 0,011 & 0,002 & 9,961 & 0,000 \\
\hline
\end{tabular}

Fonte: Elaboração dos autores baseado no programa SpaceStat.

Por meio desses três indicadores de autocorrelação espacial, podemos rejeitar a hipótese de distribuição aleatória espacial das emissões de $\mathrm{CO}_{2}$ per capita no mundo. Todos os coeficientes são altamente significativos e indicam uma autocorrelação positiva, sugerindo a existência de concentração de emissões de $\mathrm{CO}_{2}$ através do espaço. Quando as estatísticas $I$ e $c$ indicam autocorrelação positiva (concentração), significa que países com elevadas (baixas) emissões per capita estão rodeados de países também com altas (baixas) emissões per capita. Porém, quando o valor de $G$ é positivo, isso indica que essa concentração espacial é baseada no seguinte fato: países com elevadas emissões estão rodeados de países com altas emissões. Portanto, a estatística $G$ refina a informação sobre a concentração espacial fornecida pelos indicadores $I$ e $c$, sinalizando que existem mais regiões que seguem um padrão AltoAlto (AA) do que as que possuem um padrão Baixo-Baixo (BB).

Pode-se adotar também uma versão local do I de Moran ${ }^{13}$ para indicar os clusters espaciais $^{14}$ Alto-Alto (AA), Baixo-Baixo (BB), Alto-Baixo (AB) e Baixo-Alto (BA).

12 São chamadas "ilhas" aquelas regiões que não possuem fronteira geográfica com nenhuma outra localidade.

13 Para informações técnicas sobre o I de Moran local, veja Anselin (1995).

14 Os clusters apresentados pela estatística $I$ de Moran local mostram apenas aqueles estatisticamente significativos, ou seja, que exibem um padrão de associação espacial mais elevado ou mais 
Na Figura 3, observa-se que o cluster Alto-Alto é formado por países da Europa (Alemanha, Suíça, França, Holanda), do Oriente Médio (Arábia Saudita, Omã, Irã, Emirados Árabes), da América do Sul (na verdade, composto de somente um país, a Venezuela), e do Sudeste da Ásia (Malásia). Por outro lado, o cluster BaixoBaixo se concentra na África (Chade, África Central, Eritreia, Etiópia, Guiné, Costa do Marfim, Quênia, Libéria, Malawi, Mauritânia, Moçambique, Nigéria, Senegal, Serra Leoa, Sudão, Togo, Tanzânia, Uganda, Burkina Faso), Índia e Sudeste da Ásia (Tailândia e Vietnã).

Baseado nesses resultados exploratórios, não é possível verificar a hipótese da CKA. É necessário ir adiante em direção à abordagem econométrica para que se encontre a trajetória no tempo que a quantidade de carbono segue em decorrência do crescimento econômico, assim como encontrar a influência de outras variáveis na emissão desse gás de efeito estufa.

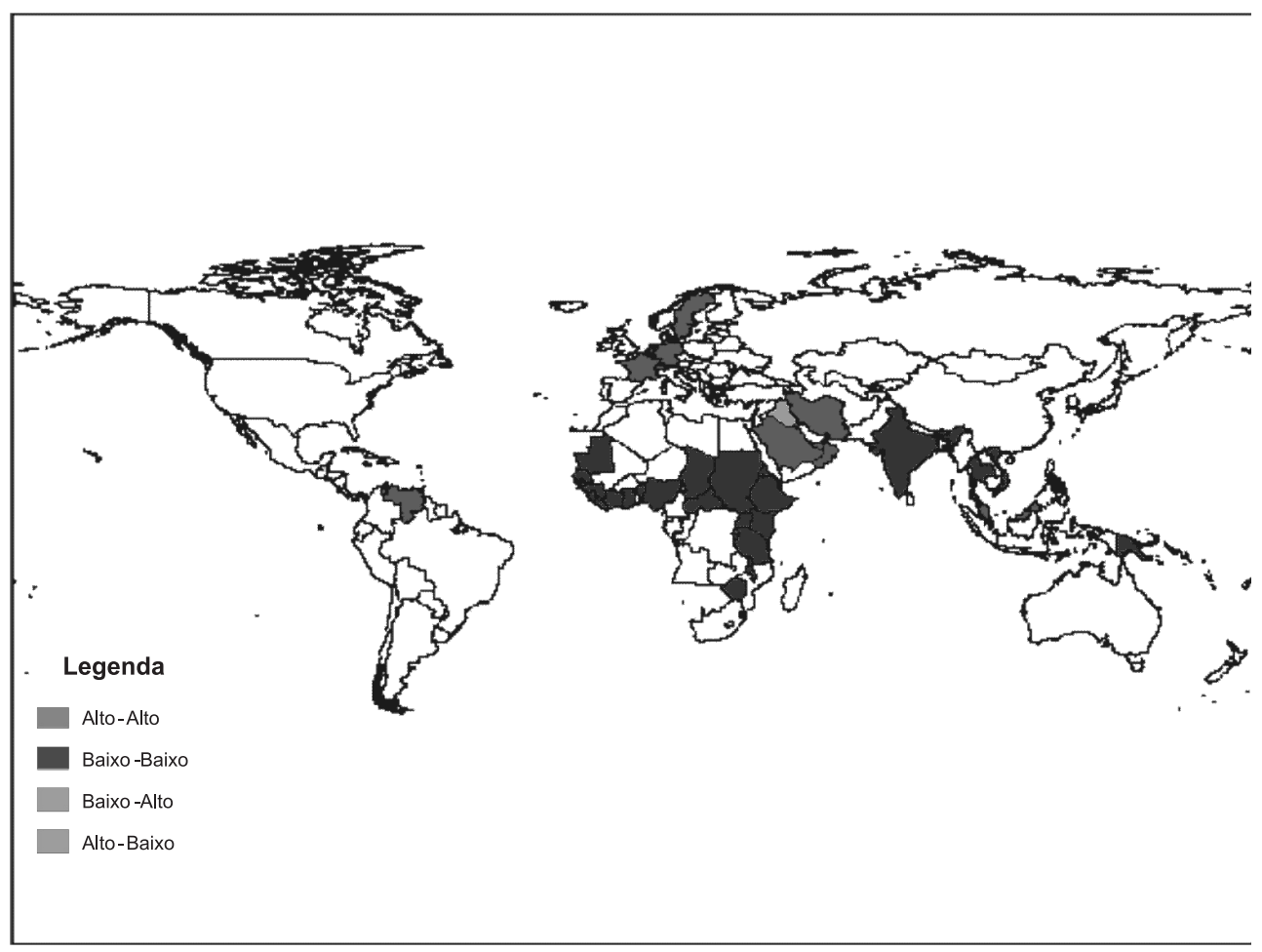

Fonte: Elaboração dos autores com base no programa GeoDa.

\section{Figura 3 - Mapa de Clusters para Emissões de $\mathrm{CO}_{2}$ Per Capita}

baixo do que a média. Portanto, os demais países da amostra (154 países que não estão presentes no mapa de clusters) não exibem esse padrão de associação, ou seja, não estão acima nem abaixo da média, em termos de significância estatística. 
Em relação à análise econométrica, inicialmente estimou-se uma regressão contra o PIB per capita, seu valor ao quadrado e as outras variáveis explanatórias pelo método MQO, sem considerar a correção espacial. A Tabela 3 reporta esses resultados.

O ajuste do modelo é extremamente elevado, medido pelo $\bar{R}^{2}$ (0,9395). Isso significa que $94 \%$ da variação da variável dependente é explicada pelas variáveis independentes colocadas do lado direito da regressão. Todos os valores dos coeficientes estimados revelam-se significativos no nível de $1 \%$, com exceção da constante que é significativa apenas no nível de $10 \%$. Os coeficientes para $Y_{i}$ e $Y_{i}^{2}$ corroboram as hipóteses CKA. Os outros coeficientes estão de acordo com a expectativa teórica, exceto o coeficiente para as exportações per capita. Em contraste, seu coeficiente apresentou-se positivo, sugerindo que existe uma relação positiva entre exportações e emissões de $\mathrm{CO}_{2}$.

Tabela 3 - Curva de Kuznets Ambiental (CKA): Resultados da Regressão por MQO

\begin{tabular}{|c|c|c|c|}
\hline Variáveis & & Coeficiente & Prob. \\
\hline Constante $(c)$ & & 0,3451 & 0,08 \\
\hline Renda Per Capita $\left(Y_{i}\right)$ & & 0,000149 & 0,00 \\
\hline Renda Per Capita ao Quadrado $\left(Y_{i}^{2}\right)$ & & $-1,839 \times 10^{-9}$ & 0,00 \\
\hline Consumo de Energia Per Capita $\left(C E_{i}\right)$ & & 2,2678 & 0,00 \\
\hline Exportações Per Capita $\left(E X_{i}\right)$ & & $5,156 \times 10^{-5}$ & 0,01 \\
\hline Protocolo de Kyoto $\left(P K_{i}\right)$ & & $-2,0144$ & 0,00 \\
\hline $\bar{R}^{2}$ & & 0,9395 & \\
\hline Número de Condição de Multicolinearidade & & 10,02 & - \\
\hline Estatística Jarque-Bera & & $1.691,28$ & 0,00 \\
\hline Teste Koenker-Basset & & 0,2 & 0,65 \\
\hline Matriz de Pesos Espaciais & Teste & Coeficiente & Prob. \\
\hline \multirow{5}{*}{ 2-vizinhos mais próximos } & LM (error) & 7,3712 & 0,01 \\
\hline & LM Robusto (error) & 8,6179 & 0,00 \\
\hline & LM (lag) & 0,2086 & 0,64 \\
\hline & LM Robusto (lag) & 1,4553 & 0,23 \\
\hline & LM (SARMA) & 8,8264 & 0,01 \\
\hline
\end{tabular}

Fonte: Elaboração dos autores com base no programa SpaceStat.

Quanto aos diagnósticos da regressão, pode-se observar que o teste Jarque-Bera indica a presença de não normalidade, ao passo que o teste Koenker-Basset confirma que os resíduos da regressão são homocedásticos. 
Os testes na Tabela 3, para dependência espacial, sugerem que a inferência baseada em uma especificação não espacial é inválida para os dados de emissões de $\mathrm{CO}_{2}$ para o conjunto de 187 países da amostra. Seguindo o procedimento de especificação proposto por Florax et al. (2003), o valor do teste de ML (Multiplicador de Lagrange) indica o modelo de erro espacial como o mais confiável. Sem considerar esse tipo de autocorrelação espacial, as estimativas por MQO geram estimativas de parâmetros ineficientes porque seus desvios padrão serão enviesados.

A Tabela 4 apresenta os resultados da estimação considerando a autocorrelação espacial em um modelo de erro, como foi sugerido pelos testes realizados acima.

Como os erros não são normais, o método de estimação utilizado foi o Método Generalizado dos Momentos proposto por Kelejian e Prucha (1999). Os resultados da regressão sugerem que existe uma relação na forma de "U" invertido na função CKA, isto é, as emissões de $\mathrm{CO}_{2}$ per capita primeiro aumentam quando a renda aumenta, porém somente até certo ponto. Após esse ponto, o aumento da renda per capita provoca a redução das emissões.

Tabela 4 - Curva de Kuznets Ambiental (CKA): Estimação do Modelo de Erro Espacial pelo Método Generalizado dos Momentos

\begin{tabular}{llc}
\hline Variáveis & Coeficiente & Prob. \\
\hline Constante $(c)$ & 0,3505 & 0,03 \\
Renda Per Capita $\left(Y_{i}\right)$ & 0,000148 & 0,00 \\
Renda Per Capita ao Quadrado $\left(Y_{i}^{2}\right)$ & $-2,049 \times 10^{-9}$ & 0,00 \\
Consumo de Energia Per Capita $\left(C E_{i}\right)$ & 2,3000 & 0,00 \\
Exportações Per Capita $\left(E X_{i}\right)$ & $4,402 \times 10^{-5}$ & 0,02 \\
Protocolo de Kyoto $\left(P K_{i}\right)$ & $-1,8412$ & 0,00 \\
Lambda $(\lambda)$ & $-0,1727$ & 0,00 \\
\hline Ponto de Inflexão & \multicolumn{2}{c}{$\$ 36.117$} \\
\hline
\end{tabular}

Fonte: Elaboração dos autores com base no programa SpaceStat.

As variáveis $Y_{i}$ e $Y_{i}^{2}$ apresentaram os sinais esperados e são significativas ao nível de $1 \%$. O ponto de inflexão encontrado foi de $\$ 36.117$, muito maior do que os valores obtidos nos estudos descritos anteriormente. Talvez, uma razão para esse valor do ponto de inflexão ter sido tão elevado seja o fato de se ter estimado um modelo espacial da CKA para as emissões de $\mathrm{CO}_{2}$ per capita. Porém, esse ponto está próximo do valor encontrado por Holtz-Eakin e Selden (1995) de \$32.428 para emissões de $\mathrm{CO}_{2}$. De modo similar, Ruphasinga et al. (2004) encontraram que, para todos os poluentes estimados em seu estudo, os pontos de inflexão da CKA ocorreram 
em altos níveis de renda em modelos espaciais, ao contrário do que aconteceu nos modelos não espaciais.

O alto valor do ponto de inflexão parece confirmar e ilustrar a natureza global do dióxido de carbono, revelando que existe pouco incentivo para as nações tomarem ações unilaterais para reduzir suas emissões, e que ações multilaterais estão sendo desenvolvidas lentamente. Apenas $6 \%$ da amostra, que são responsáveis por cerca de $20 \%$ das emissões per capita totais, se localizariam na parte descendente da curva, ou seja, em torno de $94 \%$ dos países se situariam na parte ascendente da CKA. Isso comprova que o crescimento econômico sozinho pode não levar a uma redução das emissões, e que políticas ambientais adequadas têm papel fundamental na inversão da trajetória do $\mathrm{CO}_{2}$.

O coeficiente para $C E_{i}$ é positivo e significativo também ao nível de $1 \%$, indicando que as emissões de $\mathrm{CO}_{2}$ per capita aumentam quando o consumo de energia per capita se eleva. O coeficiente para a variável $E X_{i}$, mais uma vez, não apresentou o sinal esperado, sugerindo que as crescentes exportações dos países aumentam as emissões. Porém, esse coeficiente foi significativo somente ao nível de 5\%. A razão para este coeficiente ter apresentado sinal positivo, em contraste com a expectativa teórica, se situa no fato de que os países em desenvolvimento exportam bens intensivos em energia e recursos naturais, podendo ter exercido uma maior influência na regressão.

A ratificação dos países no Protocolo de Kyoto parece reduzir as emissões de $\mathrm{CO}_{2}$ per capita, sendo que seu efeito negativo é altamente significativo. Isso parece indicar que os países que ratificaram o Protocolo estão providenciando ações de redução de emissões, e assim cumprindo o compromisso. O coeficiente de $\lambda$ apresentou-se negativo e altamente significativo, indicando que a dependência espacial no erro foi corrigida, e isto aumenta a eficiência dos estimadores.

Finalmente, estimou-se mais uma forma funcional do modelo que incluiu um termo cúbico no PIB per capita $\left(Y_{i}^{3}\right)$ para verificar se as emissões continuam decrescendo com o crescimento cada vez maior da renda. Os resultados podem ser vistos na Tabela 5. 
Tabela 5 - Curva de Kuznets Ambiental (CKA): Estimação do Modelo de Erro Espacial pelo Método Generalizado dos Momentos

\begin{tabular}{llc}
\hline Variáveis & Coeficiente & Prob. \\
\hline Constante $(c)$ & 0,0932 & 0,62 \\
Renda Per Capita $\left(Y_{i}\right)$ & 0,000286 & 0,00 \\
Renda Per Capita ao Quadrado $\left(Y_{i}^{2}\right)$ & $-8,46 \times 10^{-9}$ & 0,00 \\
Renda Per Capita ao Cubo $\left(Y_{i}^{3}\right)$ & $6,855 \times 10^{-14}$ & 0,00 \\
Consumo de Energia Per Capita $\left(C E_{i}\right)$ & 2,2753 & 0,00 \\
Exportações Per Capita $\left(E X_{i}\right)$ & $4,542 \times 10^{-5}$ & 0,02 \\
Protocolo de Kyoto $\left(P K_{i}\right)$ & $-1,8105$ & 0,00 \\
Lambda $(\lambda)$ & $-0,1565$ & 0,00 \\
\hline Ponto de Inflexão (máx.) & $\$ 16.912$ & \\
Ponto de Inflexão (mín.) & $\$ 41.137$ & \\
\hline
\end{tabular}

Fonte: Elaboração dos autores com base no programa SpaceStat.

O coeficiente para o termo cúbico do PIB é positivo e significativo, isto quer dizer que os resultados da Tabela 5 sugerem que o efeito na diminuição das emissões, quando a renda está crescendo, é transitório; pois, quando ocorrem aumentos adicionais na renda per capita, as emissões de $\mathrm{CO}_{2}$ voltam a aumentar. Esse resultado - a CKA no formato de "N" - corrobora as conclusões do trabalho de Grossman e Krueger (1991). Os demais coeficientes mantiveram-se altamente significativos e com os mesmos sinais.

Quando se incorporou o termo cúbico na regressão, o ponto de inflexão encontrado foi de $\$ 16.912$, bem menor do que aquele obtido com uma especificação quadrática da CKA. Esse valor está próximo ao encontrado por Dijkgraaf e Vollebergh (2001). Nesse caso, 15,51\% da amostra (responsável por cerca de 40\% das emissões totais) poderiam estar na parte descendente da curva. Por fim, seriam sete países na segunda parte ascendente da curva, representando pouco mais de $8 \%$ das emissões. Esse resultado, embora abrangendo mais países na parte descendente da curva, continua revelando o impacto global e o pouco incentivo para a redução da quantidade de carbono emitida.

Com a finalidade de medir o efeito de uma mudança de $1 \%$ no PIB per capita sobre as emissões de $\mathrm{CO}_{2}$ per capita, a Tabela 6 apresenta a elasticidade-renda ${ }^{15}$ das emissões para uma divisão da amostra em quatro intervalos de renda, como pode ser visto abaixo:

15 A fórmula de cálculo das elasticidades está nos anexos do presente artigo. 
Tabela 6 - Elasticidade-Renda das Emissões

\begin{tabular}{lcrc}
\hline Intervalos de Renda & Valor Mínimo & Valor Máximo & Elasticidade-renda \\
\hline Intervalo 1 (46 países) & US $\$ 94,00$ & US $\$ 617,00$ & 0,1803 \\
Intervalo 2 (47 países) & US\$ 634,00 & US\$ 2.628,00 & 0,2148 \\
Intervalo 3 (47 países) & US $\$ 2.644,00$ & US $\$ 9.953,00$ & 0,2808 \\
Intervalo 4 (47 países) & US\$ 9.189,00 & US $\$ 73.189,00$ & 0,6155 \\
\hline
\end{tabular}

Fonte: Elaboração dos autores.

Por meio da Tabela 6, observa-se que, nos intervalos mais elevados de renda, o aumento de $1 \%$ no PIB causa um impacto maior sobre as emissões de $\mathrm{CO}_{2}$. Por exemplo, no intervalo 1 , ao aumentar a renda em $1 \%$, as emissões aumentam $0,18 \%$ e, no intervalo 4 , as emissões aumentariam em $0,62 \%$. Portanto, os países mais ricos possuem uma maior elasticidade-renda em relação às emissões. Este resultado pode ter sido causado pelo fato de que, no intervalo mais elevado de renda, estão os países mais desenvolvidos, responsáveis por mais de $60 \%$ das emissões totais per capita. Assim, esses são mais sensíveis para aumentar as emissões em decorrência do aumento do PIB per capita.

\section{Considerações Finais}

Este estudo analisou a relação entre a renda per capita e as emissões de $\mathrm{CO}_{2}$ per capita em uma amostra de 187 países para o ano de 2004. A variável dependente foi regredida contra o PIB per capita, o PIB per capita ao quadrado, as exportações per capita, o consumo de energia per capita e uma dummy para indicar os países que ratificaram o Protocolo de Kyoto. Adicionalmente, um termo cúbico no PIB per capita foi incluído na forma funcional da regressão.

A hipótese da Curva de Kuznets Ambiental sugere inicialmente que a poluição segue uma trajetória na forma de "U" invertido, ou seja, que os indicadores de degradação ambiental aumentam com o crescimento da renda até atingir um nível no qual o crescimento desta passar a reduzir estes indicadores.

Ao adicionar uma forma cúbica do PIB per capita ao modelo, contudo, encontrou-se que o aumento contínuo da renda não garante o melhoramento contínuo do meio ambiente, e que a relação da CKA, no que tange às emissões de $\mathrm{CO}_{2}$, é apenas ilusória, pois países com nível mais elevado de renda voltam a apresentar aumentos nas suas emissões. Dessa forma, pode-se concluir que a relação entre renda e redução de emissões não é automática e, por meio disso, surgem possibilidades para a 
formulação de políticas públicas e acordos internacionais como forma de promover a melhoria ambiental, assim como sugerem Grossman e Krueger (1995) e Stern (2004) em seus trabalhos. Contudo, não é objetivo deste trabalho discutir quais medidas de políticas deveriam ser implementadas.

Uma das principais descobertas deste artigo foi o coeficiente altamente significativo da variável dummy, sugerindo que aqueles países que ratificaram o Protocolo de Kyoto reduziram suas emissões de $\mathrm{CO}_{2}$ em aproximadamente 1,81 toneladas métricas de carbono, ceteris paribus.

Com um formato de "N" para a CKA, aumenta a importância de políticas públicas globais que procuram obter a adesão de mais países no esforço de redução das emissões de $\mathrm{CO}_{2}$, mesmo que o ônus desse esforço não seja distribuído igualmente entre os países. Porém, mesmo que acordos de redução de emissões sejam importantes para a mitigação do efeito estufa, as metas de redução devem ser pautadas de acordo com a responsabilidade de cada país no total de emissões. O fato da CKA ser crescente em níveis elevados de renda é uma outra razão para que os países desenvolvidos que ainda não ratificaram o Protocolo o façam, pois isso poderia ter um impacto eficaz sobre a redução das emissões de $\mathrm{CO}_{2}$ e sobre o combate ao aquecimento global.

O presente estudo, ao estimar uma CKA utilizando dados em cross-section, pode estar sofrendo de um problema econométrico conhecido como viés de variáveis omitidas. Se existirem outras variáveis que afetam as emissões de $\mathrm{CO}_{2}$, mas não foram incluídas na regressão, assim como efeitos específicos de cada país devido à heterogeneidade espacial, a estimação pode estar enviesada. Ainda, a razão para resultados tão diferentes encontrados na literatura de CKA pode ser a utilização de dados cross-section, sendo que a hipótese de Kuznets original apresenta uma relação intertemporal. ${ }^{16}$ Para tratar desses problemas, sugerem-se trabalhos futuros com técnicas econométricas mais sofisticadas (por exemplo, métodos de dados em painel espacial).

Outra recomendação seria investigar melhor o papel do comércio internacional e do Protocolo de Kyoto na determinação das emissões de $\mathrm{CO}_{2}$, haja vista que esta questão tem sido pouco explorada nos trabalhos empíricos.

16 Uma discussão mais detalhada sobre a questão das análises cross-section, para uma curva de Kuznets, pode ser encontrada em Grossman (2001). 


\section{Referências}

AGRAS, J.; CHAPMAN, D. A dynamic approach to the Environmental Kuznets Curve hypothesis. Ecological Economics, New York, v. 28, p. 267-277, 1999.

ANSELIN, L. Spatial econometrics; methods and models. Kluwer. Academic, Boston, 1988, 284p.

. Local indicators of spatial association - LISA. Geographical Analysis, v. 27, n. 2, p. 93-115, 1995.

ANSELIN, L.; BERA, A.K. Spatial dependence in linear regression models with an introduction to spatial econometrics. In: ULLAH, A.Y.; GILES, D. (Ed.). Handbook of applied economic statistics. New York: Marcel Ockker, 1998. cap. 7, p. 237-289.

ARRAES, R. A.; DINIZ, M. B.; DINIZ, M. J. T. Curva ambiental de Kuznets e desenvolvimento econômico sustentável. Revista de Economia e Sociologia Rural, Rio de Janeiro, v. 44, n. 3, p. 525-547, 2006.

BAUMONT, C. Spatial effects in housing price models: do house prices capitalize urban development policies in the agglomeration Dijon (1999)? In: REGIONAL GROUP SEMINAR OF THE FEDERAL RESERVE BANK OF CHICAGO, 2004, Chicago. Disponível em: < http://ungaro.u-bourgogne.fr/baumont/e200404.pdf>. Acesso em: 4 jan. 2008.

BECKERMAN, W. Economic growth and the environment: whose growth? whose environment? World Development, Oxford, v. 20, n. 4, p. 481-496, 1992.

CARBON DIOXIDE INFORMATION ANALYSIS CENTER (CDIAC). Oak Ridge, United States of America. Disponível em: <http://cdiac.ornl.gov>. Acesso em: 15 dez. 2007.

COLE, M. A. Trade, the pollution haven hypothesis and the environmental Kuznets curve: examining the linkages. Ecological Economics, Birmingham, v. 48, p. 71-81, 2004.

COLE, M. A.; RAYNER, A. J.; BATES, J. M. The environmental Kuznets curve: an empirical analysis. Environment and Development Economics, Nottingham, v. 2, p. 401-416, 1997.

DEACON, R.; NORMAN, C. S. Is the Environmental Kuznets Curve an empirical regularity? Santa Barbara: University of California at Santa Barbara, Department of Economics, 2004. (Economics Working Paper Series 22-03).

DE BRUYN, S. M.; VAN DEN BERGH, J. C. J. M.; OPSCHOOR, J. B. Economic growth and emissions: reconsidering the empirical basis of environmental Kuznets curves. Ecological Economics, Amsterdam, v. 25, p. 161-175, 1998.

DIJKGRAAF, E.; VOLLEBERGH, H. R. J. A Note on testing for Environmental Kuznets Curves. Environmental Policy, 2001. (OCFEB Research Memorandum 0103). 
FLORAX, R. J. G. M.; FOLMER, H.; REY, S. J. Specification searches in spatial econometrics: the relevance of Hendry's methodology. Regional Science and Urban Economics, v. 33, n. 5, p. 557-579, 2003.

FONSECA, L. N.; RIBEIRO, E. P. Preservação ambiental e crescimento econômico no Brasil. In: ENCONTRO DE ECONOMIA DA REGIÃO SUL, VII, 2005. Preservação ambiental e crescimento econômico no Brasil. Rio Grande do Sul, 2005.

GALEOTTI, M.; LANZA, A. Richer and cleaner? A study on carbon dioxide emissions in developing countries. In: IAEE ANNUAL INTERNATIONAL CONFERENCE, 22 ${ }^{\text {nd }}$, 1999. Richer and cleaner? A study on carbon dioxide emissions in developing countries. Roma, 1999.

GOMES, S. C.; BRAGA, M. J. Desenvolvimento econômico e desmatamento na Amazônia Legal: uma análise econométrica. In: CONGRESSO DA SOCIEDADE BRASILEIRA DE ECONOMIA, ADMINISTRAÇÃO E SOCIOLOGIA RURAL, XLVI, 2008. Desenvolvimento econômico e desmatamento na Amazônia Legal: uma análise econométrica. Acre, 2008.

GROSSMAN, V. Inequality, economic growth, and technological change: new aspects in a old debate. Phisica-Verlag, 2001, 172 p.

GROSSMAN, G.; KRUEGER, A. Environmental impacts of a North American free trade agreement. NBER, Cambridge, MA, 1991. (National Bureau of Economic Research Working Paper 3914).

. Economic growth and the environment. Quarterly Journal of Economics, Massachussetts, v. 110, n. 2, p. 353-377, 1995.

HALKOS, G. E. Environmental Kuznets Curve for Sulfur: evidence using GMM estimation and random coefficient panel data models. Environmental and Development Economics, Volos, v. 8, p. 581-601, 2003.

HOLTZ-EAKIN, D.; SELDEN, T. M. Stocking the fires? $\mathrm{CO}_{2}$ emissions and economic growth. Journal of Public Economics, Cambridge, v. 57, n. 1, p. 85-101, 1995.

INSTITUTO DE ECONOMIA AGRÍCOLA (IEA). São Paulo, Brasil. Disponível em: <http://www.iea.sp.gov.br/OUT/verTexto.php?codTexto $=1574>$. Acesso em: 15 mar. 2008.

KAUFMANN, R. K.; DAVIDSDOTTIR, B.; GARNHAM, S.; PAULY, P. The determinants of atmospheric $\mathrm{SO}_{2}$ concentrations: reconsidering the environmental Kuznets curve. Ecological Economics, Toronto, v. 25, p. 209-220, 1998.

KELEJIAN, H. H.; PRUCHA, I. R. A Generalized moments estimator for the autoregressive parameter in a spatial model. Internacional Economic Review, v. 40, n. 2, 1999.

KUZNETS, S. Teoria do crescimento econômico moderno: taxa, estrutura e difusão. 1. ed. Rio de Janeiro: Zahar, 1966. 279p. 
LUCENA, A. F. P. Estimativa de uma Curva de Kuznets Ambiental aplicada ao uso de energia e suas implicações para as emisões de carbono no Brasil. 2005. 132f. Dissertação (Mestrado em Planejamento Energético) - Faculdade de Engenharia, Universidade Federal do Rio de Janeiro, Rio de Janeiro, 2005.

MADDISON, D. Environmental Kuznets Curves: a spatial econometric approach. Journal of Environmental Economics and Management, London, v. 51, p. 218230, 2006.

MOOMAW, W. R.; UNRUH, G. C. Are environmental Kuznets curves misleading us? The case of $\mathrm{CO}_{2}$ emissions. Environment and Development, Medfort, v. 2, p. 451-463, 1997.

PANAYOTOU, T. Empirical tests and policy analysis of environmental degradation at different stages of economic development. Technology and Employment Programme. Geneva: International Labor Office, 1993. (Working Paper WP238).

PERMAN, R.; STERN, D. I. Evidence from panel unit root and cointegration tests that the Environmental Kuznets Curve does not exist. The Australian Journal of Agricultural and Resource Economics, v. 47, n. 3, p. 325-347, 2003.

POON, J. P. H; CASAS, I.; HE, C. The impact of energy, transport and trade on air pollution in China. Eurasian Geography and Economics, New York, v. 47, p. 568-584, 2006.

RUPASINGHA, A.; GOETZ, S. J.; DEBERTIN, D. L.; PAGOUlATOS, A. The Environmental Kuznets Curve for US counties: a spatial econometric analysis with extensions. Regional Science, v. 83, p. 407-424, 2004.

SANTOS, R. B. N.; DINIZ, M. B.; DINIZ, M. J. T.; RIVERO, S. L. M.; OLIVEIRA JUNIOR, J. N. Estimativa da Curva de Kuzntes Ambiental para a Amazônia Legal. In: CONGRESSO DA SOCIEDADE BRASILEIRA DE ECONOMIA, ADMINISTRAÇÃO E SOCIOLOGIA RURAL, XLVI, 2008. Estimativa da Curva de Kuzntes Ambiental para a Amazônia Legal. Acre, 2008.

SELDEN, T. M.; SONG, D. Environmental quality and development: is there a Kuznets Curve for air pollution emissions? Journal of Environmental Economics and Management, New York, v. 27, n. 2, p. 147-162, 1994.

SHAFIK, N., BANDYOPADHYAY, S. Economic growth and environmental quality: a time series and cross-country evidence. Journal of Environmental Economics and Management, v. 4, p.1-24, 1992.

STERN, D. I.; COMMON, M. S.; BARBIER, E. B. Economic growth and environmental degradation: the Environmental Kuznets Curve and sustainable development. World Development, Massachusetts, v. 24, n. 7, p. 1151-1160, 1996.

STERN, D. I.; COMMON, M. S. Is the environmental Kuznets curve for sulfur? Journal of Environmental Economics and Management, Canberra, v. 41, n. 2, p 162-178, 2001. 
STERN, D. I. Progress on the environmental Kuznets curve? Environmental and Development Economics, Canberra, v. 3, n. 2, p. 173-196, 1998.

. Applying recent developments in time series econometrics to the spatial domain. Blackwell Publishers, Oxford, v. 52, n. 1, p. 37-49, 2000.

. Explaining changes in global sulfur emissions: an econometric decomposition approach. Ecological Economics, Canberra, v. 42, n. 1/2, p. 201-220, 2002.

. The rise and the fall of the Environmental Kuznets Curve. World Development, Troy, v. 32, n. 8, p. 1419-1439, 2004.

Global sulfur emissions from 1850 to 2000. Chemosphere, Troy, v. 58, p. 163-175, 2005.

SURI, V.; CHAPMAN, D. Economic growth, trade and energy: implications for the environmental Kuznets curve. Ecological Economics, New York, v. 25, p. 195-208, 1998.

TORRAS, M.; BOYCE, J. K. Income, inequality and pollution: a reassessment of the environmental Kuznets curve. Ecological Economics, Amherst, v. 25, p. 147-170, 1998.

UNITED NATIONS (UN). New York, United States of America. Disponível em: <http://www.un.org>. Acesso em: 15 dez. 2007.

UNITED NATIONS STATISTICS DIVISION (UNDS). New York, United States of America. Disponível em: < http://unstats.un.org/unsd/default.htm>. Acesso em: 15 dez. 2007.

WCED. Nosso futuro comum. 1. ed. Rio de Janeiro: FGV, 1987. 430p. 